\title{
Differences in Body Esteem and Sexual Assertiveness between Male and Female College Students
}

\author{
Hyun Ju Chae', Kwang Ok Lee ${ }^{2}$ \\ ${ }^{1}$ Associate Professor, Department of Nursing, Jungbu University, South Korea, ${ }^{2}$ Associate Professor, Department of \\ Nursing, Sangmyung University, South Korea
}

\begin{abstract}
The present study was conducted to identify the differences in body esteem and sexual assertiveness between male and female college students. A total of 288 students (156 males and 132 females) from a university in Chungnam, South Korea, participated in this study. A self-administered questionnaire survey with the study participants was conducted from December 1 to 14,2018 . The data obtained were analyzed using descriptive statistics, $c^{2}$ test, analysis of covariance, $t$ test, one-way analysis of variance (Scheffé test for post hoc analysis), and linear regression with the IBM SPSS 20.0 program. Body esteem among the male students was higher than that among the female students, whereas sexual assertiveness among the female students was higher than that among the male students. Body esteem differed according to body image perception in the male students and according to body image perception as well as the number of romantic relationships in the female students. Sexual assertiveness differed according to grade level and body image perception in the male students only. In all the study participants, the higher the body esteem, the higher the sexual assertiveness. These results indicate that (1) interventions that increase the body esteem of female students should be provided and (2) interventions that increase sexual assertiveness should factor in body esteem. Additionally, developmental interventions for body esteem and sexual assertiveness should consider body image perception.
\end{abstract}

Keywords: Body esteem, Sexual assertiveness, Male, Female, College students

\section{Introduction}

Body esteem refers to the evaluation of one's own body and is a multidimensional concept. ${ }^{1}$ It is a measure of one's own appearance, which includes satisfaction or dissatisfaction with physical characteristics, overall attractiveness, or the degree of investment in appearance. ${ }^{2}$ It also includes a social aspect that refers to the perception of others' evaluation of one's appearance. ${ }^{1,2}$

\section{Corresponding author:}

Kwang Ok Lee,

Associate Professor, Department of Nursing,

Sangmyung University, South Korea

E-mail: kolee@smu.ac.kr
Body esteem has been reported to affect mental health ${ }^{3}$ and to cause a variety of other health problems, such as eating disorders and inappropriate weight loss behaviors. $^{4}$

Research has shown that a number of college students think that appearance is essential to employment and romantic relationships, thereby inciting competition as well as causing low body esteem to potentially result in reduced interpersonal relationships and satisfaction regarding college life. ${ }^{5}$ Positive body esteem, motivation for achievement, and confidence in interpersonal relationships are essential not only for students' college life, academic performance, and career but also for their social life and potential married life. ${ }^{6}$ Thus, determining the body esteem of college students and identifying the factors related to their body esteem are crucial to the 
development and provision of interventions aimed at creating positive body esteem.

Body esteem can also affect the sexual health of college students. A study reported that the higher the body esteem, the higher the sexual assertiveness. ${ }^{7}$ Sexual assertiveness refers to the ability of individuals to make autonomous decisions regarding their body and sexual experiences without external coercion in a sexual situation. ${ }^{7}$ Individuals with a high level of sexual assertiveness can reject unwanted sexual behaviors, attempt desired sexual behaviors, and control their sexual desire and impulses. ${ }^{7,8}$ Hence, increasing sexual assertiveness in college students is necessary for their sexual health. Additionally, considering the results of the previously mentioned study that reported on the positive relationship between body esteem and sexual assertiveness, enhancing body esteem should be incorporated in interventions for increasing sexual assertiveness. However, research into the relationship between body esteem and sexual assertiveness is limited, which highlights the need for continuous studies and for their outcomes to be applied in interventions.

Moreover, sexual assertiveness can be influenced by various factors other than body esteem. College students are exposed to a permissive and open sex culture, thereby making sexual assertiveness vital to enable them to protect themselves from unwanted or unsafe sexual experiences. ${ }^{9}$ Thus, determining the sexual assertiveness of college students and identifying the factors related to their sexual assertiveness are essential to the development and provision of interventions intended for increasing their sexual assertiveness.

This study aimed to evaluate the body esteem and sexual assertiveness of college students, the factors associated with their body esteem and sexual assertiveness, and the relationship between their body esteem and sexual assertiveness. Since most studies have focused on women and data on men are insufficient, this study analyzed both male and female students. ${ }^{9,10}$

\section{Methods}

Study Design and Participants: A total of 288 students, of whom 156 were male and 132 were female, from a university in Chungnam, South Korea, participated in this study. Data were collected using a self-administered questionnaire from December 1 to 14,2018 . The purpose of this study and voluntary participation were explained to the students before the questionnaires were distributed. Only those who were willing to participate in the survey after the details had been discussed were asked to fill out a questionnaire. The time required to complete the questionnaire was approximately $10 \mathrm{~min}$.

Measurements: Body esteem was measured using the Body Esteem Scale developed by Mendelson et al. ${ }^{1}$ as translated by Park. ${ }^{11}$ The scale has a total of 23 items and comprises three subcategories: appearance, attribution, and body weight. Each item was measured on a five-point Likert scale, with scores ranging from 1 to 5; a higher score indicated higher body esteem. The scale's reliability was assessed using Cronbach's $a$, with values of.82 to $\sim .90$ and.79 in Park's ${ }^{11}$ study and this study, respectively.

Sexual assertiveness was measured using the scale developed by Chae. ${ }^{12}$ The scale has a total of 18 items and consists of two subcategories: refusal and demand. Each item was measured on a five-point Likert scale, with scores ranging from 1 to 5; a higher score indicated higher sexual assertiveness. Its reliability had a Cronbach's $a$ value of. 87 in Chae's ${ }^{12}$ study and that of. 85 in the present study.

Data Analysis: The collected data were analyzed using the IBM SPSS 20.0 program. The differences in general characteristics according to sex were analyzed using $c^{2}$ test. The differences in body esteem and sexual assertiveness according to sex were analyzed using the analysis of covariance to control the differences in general characteristics between the study groups. The differences in body esteem and sexual assertiveness according to general characteristics were analyzed using $t$ test and one-way analysis of variance, with the Scheffé 
test used for post hoc analysis of one-way analysis of variance. The relationship between body esteem and sexual assertiveness was analyzed via linear regression.

\section{Results}

General Characteristics: Most of the male and female students who participated in this study were in their freshman and junior years, respectively $\left(c^{2}=22.98 .76, p<.001\right)$. The male students were more overweight or obese than the female students, and the female students were more underweight than the male students $\left(c^{2}=76.89, p<.001\right)$. At the time they had their first romantic relationship, the male students were more likely to have been in elementary or middle school, whereas the female students were more likely to have been in high school or university $\left(c^{2}=10.34, p=.001\right)$. The experience of sexual intercourse was higher in the male students than in the female students $\left(c^{2}=16.76\right.$, $p<.001$ ) (Table 1).

Body Esteem and Sexual Assertiveness: As Table 1 shows, the differences in grade level, body mass index, time when they had their first romantic relationship, and experience of sexual intercourse between the male and female students were statistically significant. Thus, the differences in body esteem and sexual assertiveness according to sex were analyzed using the analysis of covariance to control these variables.

Body esteem among the male students was higher than that among the female students $(F=29.42, p<.001)$. The subcategories of appearance $(F=21.39, p<.001)$ and body weight $(F=32.51, p<.001)$ were higher in the male students than in the female students (Table 2).

Table1. Genenral characteristics $(\mathrm{N}=288)$

\begin{tabular}{|c|c|c|c|c|}
\hline \multirow[t]{2}{*}{ Characteristics } & \multirow[t]{2}{*}{ Categories } & $\begin{array}{c}\text { Male } \\
\text { students } \\
(n=156)\end{array}$ & $\begin{array}{c}\text { Female students } \\
\quad(n=132)\end{array}$ & \multirow[t]{2}{*}{$\chi^{2}(\mathrm{p})$} \\
\hline & & n (\%) & n (\%) & \\
\hline \multirow[t]{4}{*}{ Grade* } & Freshman & $57(36.8)$ & $28(21.4)$ & $22.98(<.001)$ \\
\hline & Sophomore & $37(23.9)$ & $31(23.7)$ & \\
\hline & Junior & 34 (21.9) & $61(46.6)$ & \\
\hline & Senior & $27(17.4)$ & $11(8.4)$ & \\
\hline \multirow[t]{2}{*}{ Religion* } & No & $97(63.0)$ & $75(57.3)$ & $0.97(.324)$ \\
\hline & Yes & $57(37.0)$ & $56(42.7)$ & \\
\hline \multirow[t]{4}{*}{ Body mass index } & Under weight & $1(0.6)$ & $34(25.8)$ & $76.89(<.001)$ \\
\hline & Normal & $92(59.0)$ & $92(69.7)$ & \\
\hline & Over weight & $44(28.2)$ & $5(3.8)$ & \\
\hline & Obese & $19(12.2)$ & $1(0.8)$ & \\
\hline \multirow[t]{3}{*}{ Body image perception } & Thin & $25(16.0)$ & $15(11.4)$ & $1.39(.500)$ \\
\hline & Normal & $105(67.3)$ & $92(69.7)$ & \\
\hline & Obese & $26(16.7)$ & $25(18.9)$ & \\
\hline
\end{tabular}


Cont... Table1. Genenral characteristics( $\mathrm{N}=\mathbf{2 8 8})$

\begin{tabular}{|c|c|c|c|c|}
\hline \multirow[t]{3}{*}{ Romantic relationship } & No & $18(11.5)$ & $10(7.6)$ & $5.53(.063)$ \\
\hline & 1 & $12(7.7)$ & $21(15.9)$ & \\
\hline & $\geq 2$ & $126(80.8)$ & $101(76.5)$ & \\
\hline Time of the first & $\leq$ Middle school & $83(60.1)$ & $49(40.2)$ & $10.34(.001)$ \\
\hline romantic relationship & $\geq$ High school & $55(39.9)$ & $73(59.8)$ & \\
\hline \multirow[t]{2}{*}{ Sexual intercourse } & No & $52(37.7)$ & $77(63.1)$ & $16.76(<.001)$ \\
\hline & Yes & $86(62.3)$ & $45(36.9)$ & \\
\hline \multirow[t]{2}{*}{ Pregnancy experience\# } & No & $133(97.8)$ & $114(99.1)$ & $0.71(.400)$ \\
\hline & Yes & $3(2.2)$ & $1(0.9)$ & \\
\hline \multirow[t]{2}{*}{ STI experience\# } & No & $130(95.6)$ & $113(98.3)$ & $1.44(.230)$ \\
\hline & Yes & $6(4.4)$ & $2(1.7)$ & \\
\hline & $\begin{array}{r}\text { *valid percen } \\
\text { STI }=\mathrm{Se} \\
\text { Table2. Body este }\end{array}$ & $\begin{array}{l}\text { iding partner } \\
\text { ransmitted in } \\
\text { sexual asse }\end{array}$ & $=288)$ & \\
\hline
\end{tabular}

\begin{tabular}{|c|c|c|c|}
\hline \multirow{2}{*}{ Variables } & $\begin{array}{c}\text { Male students } \\
\text { (n=156) }\end{array}$ & $\begin{array}{c}\text { Female students } \\
(\mathbf{n = 1 3 2})\end{array}$ & \multirow{2}{*}{ F (p) } \\
\cline { 2 - 4 } & $\mathbf{M} \pm$ MD & \multicolumn{2}{|c|}{} \\
\hline Body esteem & $72.49 \pm 9.79$ & $66.73 \pm 9.67$ & $29.42(<.001)$ \\
\hline Appearance & $31.60 \pm 4.79$ & $29.42 \pm 4.41$ & $21.39(<.001)$ \\
\hline Attribution & $15.19 \pm 3.59$ & $14.58 \pm 3.59$ & $3.06(.081)$ \\
\hline Body weight & $25.71 \pm 4.58$ & $22.79 \pm 4.18$ & $32.51(<.001)$ \\
\hline Sexual assertiveness & $64.03 \pm 11.46$ & $67.80 \pm 11.57$ & $7.41(.007)$ \\
\hline Refusal & $33.83 \pm 7.13$ & $37.36 \pm 7.13$ & $13.76(<.001)$ \\
\hline Demand & $30.20 \pm 7.40$ & $30.44 \pm 7.94$ & $30.16(.523)$ \\
\hline
\end{tabular}

Body Esteem according to General Characteristics: Body esteem was higher in male $(\mathrm{F}=6.53, p=.002)$ and female $(\mathrm{F}=3.69, p=.028)$ students who perceive their body image as thin or normal than those who perceive their body image as obese. Body esteem was also higher in female students who did not experienced romantic relationship or who experienced two or more romantic relationship than those who experienced only one romantic relationship $(\mathrm{F}=3.23, p=.043)($ Table 3). 
Sexual Assertiveness According to General Characteristics: In the male students, sexual assertiveness among the sophomores was higher than that among the freshmen and seniors $(F=2.75$, $p=.045)$. Similarly, sexual assertiveness among the male students who perceived themselves as normal or obese was higher than that among those who perceived themselves as thin $(F=4.65, p=.011)$. In the female students, sexual assertiveness did not differ according to general characteristics (Table 4).

Table 3. Body esteem according to genenral characteristics $(\mathrm{N}=\mathbf{2 8 8})$

\begin{tabular}{|c|c|c|c|}
\hline \multirow{2}{*}{ Characteristics } & \multirow{2}{*}{ Categories } & $\begin{array}{l}\text { Male students } \\
\qquad(\mathrm{n}=156)\end{array}$ & $\begin{array}{l}\text { Female students } \\
\quad(n=132)\end{array}$ \\
\hline & & $\mathbf{M} \pm \mathbf{S D}$ & $\mathbf{M} \pm \mathbf{S D}$ \\
\hline \multirow[t]{5}{*}{ Grade } & Freshman & $69.89 \pm 9.16$ & $65.36 \pm 10.20$ \\
\hline & Sophomore & $75.14 \pm 9.54$ & $68.13 \pm 9.74$ \\
\hline & Junior & $73.56 \pm 9.03$ & $66.63 \pm 9.38$ \\
\hline & Senior & $72.07 \pm 10.59$ & $67.18 \pm 10.77$ \\
\hline & $\mathrm{F}(\mathrm{p})$ & $2.53(.059)$ & $0.41(.749)$ \\
\hline \multirow[t]{3}{*}{ Religion } & No & $72.34 \pm 8.98$ & $65.77 \pm 9.49$ \\
\hline & Yes & $72.35 \pm 10.86$ & $61.88 \pm 11.15$ \\
\hline & $\mathrm{t}(\mathrm{p})$ & $-0.01(.995)$ & $-1.40(.166)$ \\
\hline \multirow[t]{4}{*}{ Body mass index } & Under weight & $74.00 \pm 0.00$ & $69.30 \pm 10.16$ \\
\hline & Normal & $73.57 \pm 8.87$ & $66.20 \pm 9.49$ \\
\hline & $\geq$ Over weight & $70.89 \pm 10.95$ & $60.67 \pm 5.96$ \\
\hline & $\mathrm{F}(\mathrm{p})$ & $1.42(.246)$ & $2.55(.082)$ \\
\hline \multirow[t]{4}{*}{ Body image perception } & Thin & $72.08 \pm 9.38 \mathrm{a}$ & $68.80 \pm 9.86 a$ \\
\hline & Normal & $74.05 \pm 9.93 a$ & $67.64 \pm 9.89 \mathrm{a}$ \\
\hline & Obese & $66.58 \pm 7.31 \mathrm{~b}$ & $62.16 \pm 7.43 b$ \\
\hline & $\mathrm{F}(\mathrm{p})$ & $6.53(.002) \mathrm{a}>\mathrm{b}$ & $3.69(.028) \mathrm{a}>\mathrm{b}$ \\
\hline \multirow[t]{4}{*}{ Romantic relationship } & No & $70.89 \pm 7.50$ & $69.90 \pm 11.29 \mathrm{a}$ \\
\hline & 1 & $71.50 \pm 14.77$ & $62.14 \pm 8.95 b$ \\
\hline & $\geq 2$ & $72.81 \pm 9.56$ & $67.37 \pm 9.44 a$ \\
\hline & $\mathrm{F}(\mathrm{p})$ & $0.37(.694)$ & $3.23(.043) \mathrm{a}>\mathrm{b}$ \\
\hline Time of the first & $\leq$ Middle school & $72.49 \pm 9.53$ & $66.06 \pm 10.51$ \\
\hline \multirow[t]{2}{*}{ romantic relationship } & $\geq$ High school & $73.00 \pm 10.88$ & $66.73 \pm 8.89$ \\
\hline & $\mathrm{t}(\mathrm{p})$ & $-0.28(.779)$ & $-0.36(.719)$ \\
\hline \multirow[t]{3}{*}{ Sexual intercourse } & No & $71.81 \pm 10.38$ & $65.89 \pm 9.16$ \\
\hline & Yes & $73.23 \pm 9.88$ & $67.42 \pm 10.15$ \\
\hline & $\mathrm{t}(\mathrm{p})$ & $-0.80(.428)$ & $-0.83(.409)$ \\
\hline
\end{tabular}


Medico-legal Update, October-December 2021, Vol.21, No. 4

Relationship Between Body Esteem and Sexual Assertiveness: In both the male and female students, the higher body esteem was, the higher sexual assertiveness was (Table 5).

Table 4. Sexual assertiveness according to genenral characteristics $(\mathrm{N}=\mathbf{2 8 8})$

\begin{tabular}{|c|c|c|c|}
\hline \multirow{2}{*}{ Characteristics } & \multirow{2}{*}{ Categories } & $\begin{array}{l}\text { Male students } \\
\qquad(n=156)\end{array}$ & $\begin{array}{l}\text { Female students } \\
\qquad(\mathrm{n}=132)\end{array}$ \\
\hline & & $\mathbf{M} \pm \mathbf{S D}$ & $\mathbf{M} \pm \mathbf{S D}$ \\
\hline \multirow[t]{5}{*}{ Grade } & Freshman & $61.60 \pm 12.67^{a}$ & $67.29 \pm 10.60$ \\
\hline & Sophomore & $67.35 \pm 10.59^{b}$ & $67.94 \pm 10.49$ \\
\hline & Junior & $66.18 \pm 11.04$ & $68.54 \pm 12.38$ \\
\hline & Senior & $61.67 \pm 9.21^{\mathrm{a}}$ & $64.18 \pm 13.35$ \\
\hline & $\mathrm{F}(p)$ & $2.75(.045)^{\mathrm{a}<\mathrm{b}}$ & $0.45(.716)$ \\
\hline \multirow[t]{3}{*}{ Religion } & No & $64.98 \pm 11.33$ & $67.85 \pm 12.86$ \\
\hline & Yes & $61.88 \pm 11.15$ & $67.36 \pm 9.38$ \\
\hline & $\mathrm{t}(p)$ & $1.66(.100)$ & $0.24(.807)$ \\
\hline \multirow[t]{4}{*}{ Body mass index } & Under weight & $59.00 \pm 0.00$ & $67.76 \pm 8.43$ \\
\hline & Normal & $63.49 \pm 12.50$ & $67.70 \pm 12.18$ \\
\hline & $\geq$ Over weight & $64.89 \pm 9.85$ & $69.67 \pm 18.28$ \\
\hline & $\mathrm{F}(p)$ & $0.37(.689)$ & $0.08(.922)$ \\
\hline \multirow[t]{4}{*}{ Body image perception } & Thin & $58.28 \pm 10.71^{\mathrm{a}}$ & $71.00 \pm 8.72$ \\
\hline & Normal & $64.53 \pm 11.58^{b}$ & $68.40 \pm 11.55$ \\
\hline & Obese & $67.50 \pm 9.96^{\mathrm{b}}$ & $63.68 \pm 12.46$ \\
\hline & $\mathrm{F}(p)$ & $4.65(.011)^{\mathrm{a}<\mathrm{b}}$ & $2.33(.101)$ \\
\hline \multirow[t]{4}{*}{ Romantic relationship } & No & $67.44 \pm 10.21$ & $68.70 \pm 20.89$ \\
\hline & 1 & $60.58 \pm 14.05$ & $67.29 \pm 10.03$ \\
\hline & $\geq 2$ & $63.87 \pm 11.33$ & $67.82 \pm 10.76$ \\
\hline & $\mathrm{F}(p)$ & $1.36(.259)$ & $0.05(.951)$ \\
\hline Time of the first & $\leq$ Middle school & $64.06 \pm 11.79$ & $66.55 \pm 10.24$ \\
\hline \multirow[t]{2}{*}{ romantic relationship } & $\geq$ High school & $62.85 \pm 11.30$ & $68.52 \pm 10.83$ \\
\hline & $\mathrm{t}(p)$ & $0.60(.547)$ & $-1.02(.311)$ \\
\hline \multirow[t]{3}{*}{ Sexual intercourse } & No & $64.02 \pm 12.98$ & $67.40 \pm 10.43$ \\
\hline & Yes & $63.31 \pm 10.70$ & $68.29 \pm 10.98$ \\
\hline & $\mathrm{t}(p)$ & $0.33(.742)$ & $-0.44(.662)$ \\
\hline
\end{tabular}


Table 5. Relationship between body esteem and sexual assertiveness $(\mathrm{N}=\mathbf{2 8 8})$

\begin{tabular}{|c|c|c|c|c|c|c|}
\hline Gender & Variable & B & SE & $\boldsymbol{\beta}$ & $\mathbf{t}$ & $\mathbf{p}$ \\
\hline \multirow{2}{*}{$\begin{array}{l}\text { Male students } \\
\quad(\mathrm{n}=156)\end{array}$} & Constant & 32.79 & 7.94 & & 4.13 & $<.001$ \\
\hline & Body esteem & 0.29 & 0.09 & 0.24 & 3.05 & .003 \\
\hline & \multicolumn{6}{|c|}{$\mathrm{R} 2=0.11, \operatorname{Adj} \mathrm{R} 2=0.09, \mathrm{~F}=6.10, \mathrm{p}=.001$} \\
\hline \multirow{2}{*}{$\begin{array}{c}\text { Female students } \\
\qquad(\mathrm{n}=132)\end{array}$} & Constant & 50.14 & 6.95 & & 7.22 & $<.001$ \\
\hline & Body esteem & 0.27 & 0.10 & 0.22 & 2.58 & .001 \\
\hline & \multicolumn{6}{|c|}{$\mathrm{R} 2=0.049, \operatorname{Adj} \mathrm{R} 2=0.042, \mathrm{~F}=6.64, \mathrm{p}=.011$} \\
\hline
\end{tabular}

\section{Discussion and Conclusions}

In this study, body esteem among the male college students was higher than that among the female college students. This result is congruent with the outcomes obtained by previous studies. Thus, various and efficient interventions aimed at increasing the body esteem of female college students are required. This study found that body esteem is lower among the male and female college students who perceived themselves as obese than among those who perceived themselves as thin or normal. Therefore, interventions for body esteem should consider body image perception. Studies have reported that college students often had a distorted body image. The results of the present and previous studies suggest that (1) whether college students correctly perceive their body image should be determined and (2) interventions that enable them to correctly perceive their body image should be preferentially provided.

This study also found that sexual assertiveness differs according to body image perception. Hence, interventions for sexual assertiveness should consider body image perception as well. Moreover, this study found that in both the male and female college students, the higher body esteem is, the higher sexual assertiveness is, which is consistent with previously reported data. Thus, interventions to increase sexual assertiveness should also factor in body esteem.

\section{Conflict of Interest : Nil}

\section{Ethical Clearance: None}

\section{Source of Funding : Self}

\section{References}

1. Mendelson BK, Mendelson MJ, White DR. Body esteem scale for adolescents and adults. Journal of Personality Assessemnt. 2001;76:90-106.

2. Confalonieri E, Gatti E, Ionio C, Traficante D. Body esteem scale: A validation on Italian adolescents. Testing, Psychometrics, Methodology in Applied Psychology. 2008;15(3):153-165.

3. Otakpor AN, Ehimigbai M. Body image perception and mental health of in-school adolescents in Benin city, Nigeria. The Nigerian Postgraduate Medical Journal. 2016;23(2):71-78.

4. Bibiloni Mdel M, Pich J, Pons A, Tur JA. Body image and eating patterns among adolescents. BMC public health. 2013;13:1104. 
5. Kim YS. The effect on college life satisfaction accroding to appearance satisfaction of liberal arts beauty course by university students on campus based on holistic education. Jouranl of Holistic Education. 2013;17(3):17-41.

6. Yun EY. Differences in achivement motivation and personal relations according to students' degree of satisfaction with appearance. Master's thesis. 2013. Chungnam National University. Daejeon:Korea.

7. Auslander BA, Baker J, Short MB. The connection between young women's body esteem and sexual assertiveness. Journal of Pediatric and Adolescent Gynecology. 2012;25(2):127-130.

8. Kim KW, Kang KH, Jeong GH. Self efficacy and sexual autonomy among university students. Journal of Korean Public Health Nursing. 2012;26:51-59.

9. Kim YH, Moon ST, Kang HS. Factors influencing on sexual assertiveness of college students. Koran Journal of Women Health Nursing. 2013;19(3):166175.

10. Yom YH, Lee KE. Factors affecting body image of undergraduate students. Journal of Korean Academy of Fundamental Nursing. 2011;18(4):452-462.

11. Park WC. The effect of adolescent's body mass index, self-esteem, family criticism and media exposure on their body image [master's thesis]. [Seoul]:Yonsei University. 2009.

12. Chae HY. Relationships between body type perception and emotional intelligence and sexual assertiveness of female college students. Jouranl of Digital Convergence. 2019;17(7):197-205. 